\title{
A (RE)CONSTRUÇÃO DA NOÇÃO ESPACIAL ATRAVÉS DA TECNOLOGIA DO SENSORIAMENTO REMOTO: o desenho, as imagens orbitais e o texto.
}

\section{A (RE)CONSTRUCTION OF THE SPATIAL NOTION THROUGH THE REMOTE SENSING TECHNOLOGY: the drawing, the orbital images and the text.}

Donarte Nunes dos Santos Júnior, Especialista no Ensino de Geografia, Mestre em Educação em Ciência e Matemática e Mestrando em Filosofia (PUCRS) donarte.santos@pucrs.br

Regis Alexandre Lahm, Doutor em Engenharia de Recursos Hídricos, coordenador do Laboratório de Tratamento de Imagens e Geoprocessamento (PUCRS) lahm@pucrs.br

\section{RESUMO}

O presente texto se situa entre um relato de pesquisa e um artigo. Assim, o texto apresenta uma profunda revisão de literatura seguida da apresentação de resultados de uma pesquisa já desenvolvida, através de uma dissertação de mestrado. O problema que a pesquisa tentou responder está relacionado a três questões básicas, a saber, (i) ao modo como estudantes de uma escola particular expressam, através do desenho, o espaço, o lugar onde vivem, (ii) às (re)construções que esses mesmos educandos fazem ao deparar seus desenhos com imagens orbitais, produtos advindos da tecnologia do Sensoriamento Remoto que retratam os referidos lugares e (iii) como essa noção, agora (re)construída, é expressa através de um texto.

Palavras-chave: Noção espacial. Desenho. Imagens orbitais. Texto.

\section{ABSTRACT}

The current text goes between a research report and an article. Thus, it presents a deep revision of literature followed by results from a research already developed, through a master's dissertation. The problem that the research tried to answer is related to three basic issues, namely, (i) the way students of a private school convey, through drawing, the space, the place where they live, (ii) the (re)constructions that the same students make when they compare their drawings with satellite images, products that came from Remote Sensing technology which portrait such places and (iii) how that notion, now (re)constructed, is shown through a text.

Keywords: Spatial notion. Drawing. Orbital images. Text.

\section{INTRODUÇÃO}

Modernos sensores orbitais $^{1}$; aparelhos óptico-eletrônicos lançados na orbita terrestre por meio de foguetes, que acabam por integrar as plataformas chamadas, senso comum, de satélites artificiais fizeram com que o geóide passasse a ser estudado por

\footnotetext{
${ }^{1}$ Cabe lembrar que sensor orbital é o aparelho óptico-eletrônico que, de fato, detecta e registra, sob a forma de uma imagem, a reflectância (que é a propriedade intrínseca de um alvo, que pode variar entre 0 e 1, e que, posteriormente, é convertida em radiância (que é a propriedade intrínseca da "radiação eletromagnética”, que tem sua variação ao longo do ano, conforme as estações)) proveniente de um alvo na superfície terrestre ou em sua atmosfera. O satélite, propriamente dito, é tão somente a plataforma, o "invólucro" metálico que abriga o sensor orbital. Assim, tecnicamente, terminologias, tais como, "satélite artificial” e "imagem de satélite” não são estritamente corretas, devendo, sugere-se, ser substituída por "sensores orbitais” e "imagens orbitais".
} 
meio de tecnologias cada vez mais apuradas: surgiam as geotecnologias ${ }^{2}$. Na Geodésia, finas aferições permitem o conhecimento de medidas precisas, tais como, as do monte Everest (altimetria ${ }^{3}$ de $8.848 \mathrm{~m}$ ), no Himalaia, as da fossa de Mindanao (batimetria ${ }^{4}$ de $11.524 \mathrm{~m})$, no conjunto das Fossas das Marianas, no Oceano Pacífico ou mesmo a velocidade de distanciamento dos continentes, estimada, mais recentemente, em 2cm/ano (cf. POPP, 1998). A precisão centímetrica, levando-se em consideração a circunferência terrestre que é de, aproximadamente, $44.000 \mathrm{Km}$ é excelente.

O sensoriamento remoto ${ }^{5}$ e os produtos advindos dele, que avançam concomitantemente com as supramencionadas inovações, desde então, proporcionam observações de alvos terrestres a partir de imagens orbitais com resoluções espaciais ${ }^{6}$ cada vez maiores ${ }^{7}$. Esses imageamentos têm auxiliando em diagnósticos ambientais, sócio-econômicos, políticos e culturais. Não é mais possível desconsiderar esse tipo de tecnologia, e, nesse sentido, para que uma sociedade tecnológica subsista e progrida, é necessário que se eduque com o escopo de formar cidadãos que saibam lidar com esses avanços.

No âmbito educacional legal, são previstas medidas que inserem as tecnologias no processo educativo, a fim de se formar sujeitos capacitados para atuar numa sociedade tecnológica. A LDB (Lei 9.394/96) defende uma educação escolar que trabalhe com conteúdos e recursos que qualifiquem o cidadão para viver em tal sociedade. Os PCN's e as DCN's, com suas normatizações para o ensino fundamental e médio, apontam para a importância do trabalho com o conhecimento científico e tecnológico na Educação Básica. Urge, assim, a introdução das tecnologias no Ensino Fundamental e Médio.

Diante deste contexto sócio-histórico, o presente artigo pretende fazer eco de resposta ao chamado, já antigo, de união entre educação e tecnologia. Busca fazer isso, especificamente, com uma pesquisa que investiga como estudantes do Ensino Médio concebem, mentalmente, a imagem do lugar onde vivem e (re)contróem essa imagem após a visualização de imagens orbitais. Por outros termos, o presente artigo é resultado de um estudo que procurou investigar a percepção espacial de alunos do ensino médio, tentando responder à seguinte pergunta: “Como educandos de uma escola particular de ensino concebem a imagem do espaço onde vivem e como estes mesmos estudantes (re)constroem, posteriormente, essa imagem tendo por base imagens orbitais".

\section{FUNDAMENTAÇÃO TEÓRICA}

\subsection{O SENSORIAMENTO REMOTO}

“Voar: verrer o céo, com azas poderosas,

\footnotetext{
2 Tecnologias relacionadas à Terra, presentes, principalmente, no campo da Geodésia. Em especial, neste trabalho, geotecnologias com referência ao Sensoriamento Remoto.

${ }^{3}$ A altimetria é a medida da altitude, tomando por base o nível do mar.

${ }^{4}$ A batimetria é a medida da profundidade, tomando por base o nível do mar.

${ }^{5}$ Segundo Lahm (2000), o sensoriamento remoto é a "tecnologia que permite a obtenção de informações sobre diferentes alvos ou fenômenos, na superfície da Terra e em sua atmosfera, sem o contato físico com os mesmos." (p. 66).

${ }^{6}$ A resolução espacial é uma medida de grandeza que corresponde ao tamanho da célula mínima de uma imagem, denominada de pixel (do inglês picture element).

${ }^{7}$ Ainda sobre as resoluções espaciais dos atuais sensores orbitais é interessante destacar o alto nível de detalhe que eles proporcionam ao observador. Sensores, tais como, o Digital Globe e/ou o Terra Metrics, ambos estadounidenses, têm uma resolução tão potente que permite a visualização de automóveis e pessoas atravessando ruas.
} 
Sobre as nuvens!”

(Olavo Bilac, em poema em homenagem a Bartolomeu Lourenço de Gusmão, o inventor da aeroestação)

Poder voar para ver a Terra do alto sempre foi sonho do homem. Mais de um século após as primeiras aventuras nos aeróstatos de hélio e da invenção da máquina fotográfica $^{8}$, as técnicas de sensoriamento remoto continuam evoluindo. O sensoriamento remoto é uma tecnologia capaz de colaborar em ampla gama de estudos multi e trans disciplinares. Restrita, antigamente, aos laboratórios especializados e aos Quartéis Generais militares, passa hoje a ser ferramenta usada por uma ampla gama de setores civis, inclusive a escola.

Hoje o sensoriamento remoto é tecnologia ${ }^{9}$ que se caracteriza por ser ferramenta que potencializa a análise feita por geógrafos, meteorologistas, geólogos, engenheiros, arqueólogos, e, mais recentemente, por administradores e professores; e não só os de geografia, mas os de outras disciplinas, como matemática, biologia, química, física, artes e outras (cf. SANTOS V., 1998, 1999, 2002; SANTOS JÚNIOR, 2007).

Existem inúmeros satélites artificiais orbitando nosso planeta. Somente o sistema GPS ${ }^{10}$ conta com vinte e quatro deles. Desde que, em 1972, os Estados Unidos lançaram o primeiro satélite de observação da Terra, os satélites da série Landsat, várias instituições especializadas, como a Unidet Satates Geological Survey, dos Estados Unidos, o Institut Géografich National, da França, e outras, têm enviado mais e mais sensores ao espaço. Nesse sentido, o lixo espacial já é sério problema, mas, como esse não é o escopo do presente texto, passe-se adiante ${ }^{11}$.

A fonte de energia necessária para que um sensor capte uma imagem pode ser de dois tipos (SANTOS, V., 1998, 1999, 2002); o primeiro, serve-se do espectro solar; o segundo, da radiação eletromagnética ${ }^{12}$ (RAM) emitida por ele próprio. Tais aparelhos são chamados, freqüentemente, de sensores passivos e ativos, respectivamente. Assim, para o primeiro caso, a ilustração abaixo representa a forma e as condições para que um

\footnotetext{
${ }^{8}$ Pode-se dizer que o sensoriamento remoto encontra suas raízes nos primórdios da aeroestação e da máquina fotográfica. A aeroestação foi inventada pelo padre jesuíta Bartolomeu de Gusmão (16851724), que lançou seu primeiro aeróstato (balão) frente ao rei de Portugal no ano de 1709. A máquina fotográfica foi inventada por Joseph Nicéphore Niépce (1765-1833), químico francês, que gravou sua primeira fotografia permanente (as outras desapareciam rapidamente) da janela do sótão de sua casa de campo no ano de 1826, utilizando-se, para isso, de uma câmara escura. Niépce batizou o processo de heliografia (termo de origem grega que significa literalmente "grafia solar", ou seja, gravar com a luz do Sol). Posteriormente, Niépce associou-se a Louis-Jacques-Mandré Daguerre (1787-1851), comerciante e pesquisador francês. Conta-se que este último descobriu acidentalmente a "revelação" fotográfica: ele teria exposto uma placa revestida com iodeto de prata para ser sensibilizada (heliografia), como após certo tempo a placa não reproduziu uma imagem do alvo, Daguerre guardou-a inadvertidamente numa gaveta. No dia seguinte, surpresa: a fotografia havia sido "revelada”, pois havia ficado num local escuro. Daguerre batizou seu sistema de Daguerreótipo (BORGES, 2005).

9 A respeito disso, cabe dizer que se compartilha o entendimento de Vesentini (2005), definindo tecnologia como uma técnica avançada, resultante da aplicação de conhecimento científico, da ciência moderna que nasceu - ou se consolidou - nos séculos XVII e XVII e prossegue até os nossos dias.

${ }^{10}$ Trata-se de sistema de satélites artificiais concebido pelos norte-americanos (década de 1960) para fins militares e liberados para uso civil em 1995.

${ }^{11}$ A respeito da questão do lixo espacial, e com um proposta parecida com a do presente texto, os presentes autores recomendam a leitura de: REIS, Norma Teresinha Oliveira et al. Análise da dinâmica de rotação de um satélite artificial: uma oficina pedagógica em educação espacial. Rev. Bras. Ensino Fís., São Paulo, v. 30, n. 1, 2008. Disponível em:

$<$ http://www.scielo.br/scielo.php?script=sci_arttext\&pid=S1806-

11172008000100011\&lng=en\&nrm=iso>. access on 24 Mar. 2010, especialmente o ítem 2.

12 Segundo Hecht (2002): "Heinrich Rudolf Hertz (1857-1894) confirmou a existência de ondas electromagnétiocas, produzindo-as e detectando-as, ao longo de uma extensa série de experiências publicadas em 1888.” (p. 23).
} 
sensor possa captar uma imagem (Figura 1) - para o caso dos sensores passivos, bastase imaginar, por exemplo, um radar, um ecobatímetro ${ }^{13}$ ou um $\operatorname{sonar}^{14}$ :

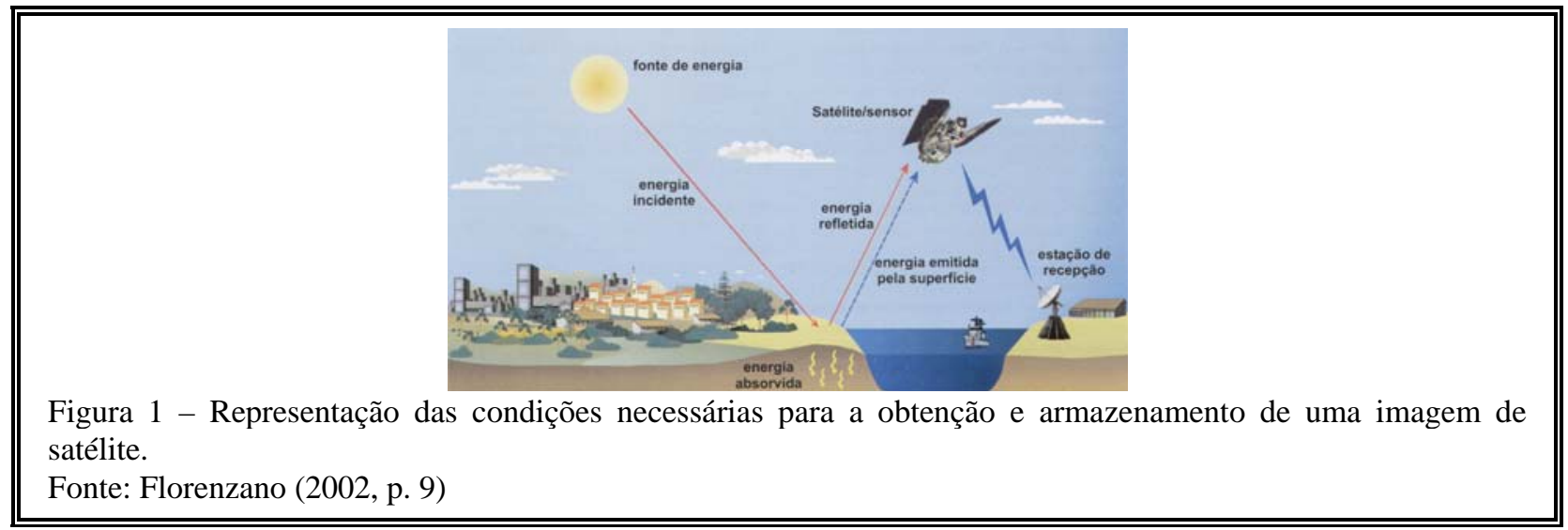

Relativamente à ilustração acima (Figura 1), Boligian e Boligian (2004) explicam que a energia solar refletida pela superfície terrestre é captada pelo sensor, transformada em sinais elétricos, que são registrados e transmitidos para as estações de recepção em terra firme. A partir daí, esses sinais são transformados nos mais diversos produtos que podem ser tabelas, gráficos ou imagens ${ }^{15}$.

Segundo Florenzano (2002), todos os corpos emitem energia; desde que não estejam, é claro, a uma temperatura de $0^{\circ} \mathrm{K}\left(-273,5^{\circ} \mathrm{C}\right)$. Essa energia se manifesta na forma de ondas eletromagnéticas a uma velocidade de, aproximadamente, 300.000 $\mathrm{km} / \mathrm{s}$. Esse espectro pode ser medido em freqüencia (medida em hertz) e em comprimento de onda (medidas em unidades de comprimento que vão de mícrons a quilômetros). Existem muitas freqüências e comprimentos de onda conhecidos hoje. Ao conjunto dessas ondas chama-se espectro eletromagnético ${ }^{16}$. Vide ilustração a seguir (Figura 2):

\footnotetext{
${ }^{13}$ Ecobatímetro: é aqui acrescentado entre os sensores ditos "ativos", pois emite seu próprio impulso eletromagnético. O ecobatímetro registra e apresenta numa tela, por exemplo, a medição do tempo decorrido entre a emissão de um pulso sonoro, de freqüência sônica ou ultra-sônica, e a recepção do mesmo sinal após ser refletido pelo assoalho do corpo d'água (lago, rio, oceano, etc.). O tempo que o som leva entre o momento de sua emissão e o de sua recepção determina a profundidade.

${ }^{14}$ Os sonares, semelhantemente aos ecobatímetros, emitem seu próprio comprimento de onda que reflete no alvo e volta trazendo informações sobre o mesmo.

${ }^{15}$ Uma imagem pode ser visualizada em sua forma pictórica; conforme uma imagem propriamente dita, e pode, também, ser analisada como uma matriz matemática (CRÓSTA, 1992), conforme o exemplo que segue: que pode ser visto assim:

${ }^{16}$ A respeito do espectro eletromagnético, Hecht (2002) informa que: "Em 1867, quando Maxwell publicou pela primeira vez detalhadamente a sua teoria de campo electromagnético, o espectro de freqüências conhecido estendia-se apenas do infravermelho, através do visível, até o ultravioleta. Apesar desta região ser de primordial importância em Óptica, ela constitui apenas um pequeno segmento do vasto espectro electromagnético.” (p. 101). Em seguida, o mesmo teórico identifica alguns desses comprimentos de onda, quais sejam, ondas de radiofreqüencia, Microondas, Infravermelho, luz, ultravioleta, raios X e raios gama. Para ir além, é interessante se ler: HECHT, Eugene. Óptica. Tradução José Manuel N. V. Rebordão. 2. ed. Lisboa: Fundação Calouste Gulbenkian, 2002, às páginas 101 a 111.
} 


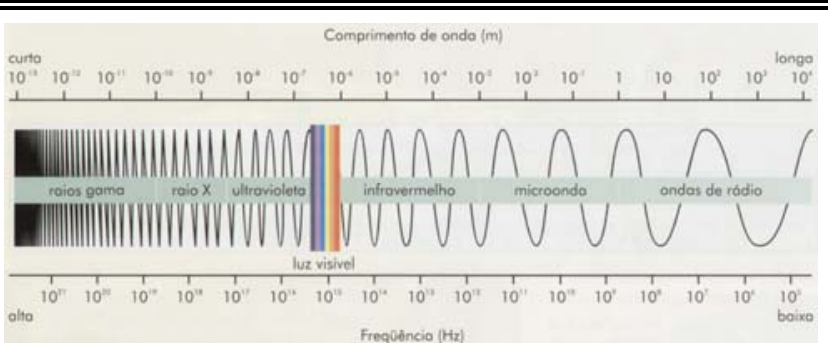

Figura 2 - Representação do comportamento das ondas do espectro eletromagnético.

Fonte: Florenzano (2002, p. 11)

No Brasil, os principais órgãos governamentais que dispõem de produtos advindos do sensoriamento remoto são o $\operatorname{INPE}^{17}$ e o $\operatorname{IBGE}^{18}$, que têm à disposição imagens digitais de várias partes do planeta, sobretudo do Brasil.

Existem sensores para análise atmosférica, para análise geológica, monitoramento de florestas e até para uso do Estado, que pode fiscalizar uso agrícola do solo e colaborar com cadastros multifinalitários, tais como, o cadastramento e a cobranças de IPTU.

Conclui-se encaminhando o seguinte entendimento: apesar de o sensoriamento remoto e seus produtos serem, freqüentemente, considerados como " $a$ verdade" acerca daquilo que representam, eles nada mais são do que meras ferramentas que, sobretudo na escola, transformar-se-ão em recursos didáticos ${ }^{19}$. Devem, pois, serem estudados e com base numa visão crítica.

\subsection{A IMAGEM}

“O mundo percebido através dos olhos é mais abstrato do que o concebido por nós através de outros sentidos.” (TUAN, 1980, p. 12)

Dos sentidos que o ser humano possui, a visão, pela qual lhe vem imagens, é a mais abstrata, porque se dá de uma forma, por assim dizer, quase indireta; sem um contato físico mais imediato, tal como o tato. O que é a imagem? Barthes (1990) identifica a etimologia do termo imagem na palavra latina imitare. O semiólogo faz referência distante, antiga e possível etimologia advinda dos termos latinos imitābìlis,

17 O INPE disponibiliza parte do acervo de suas imagens digitais sob o endereço eletrônico: http://www.dgi.inpe.br/CDSR/

${ }^{18}$ Segundo recente notícia (21/12/2006) o IBGE e a Alaska Satellite Facility (ASF), da Universidade do Alaska, assinaram uma acordo de cooperação para distribuição de imagens deste satélite a órgãos do governo brasileiro. Segundo a notícia, um dos grandes diferenciais destas imagens é que serão fornecidas pela ASF de baixo custo. O satélite ALOS foi lançado pela Agência Espacial Japonesa (JAXA) no dia 24 de janeiro de 2006. transporta dois sensores ópticos, que obtêm imagens coloridas do planeta com resolução de 10 metros, e imagens tridimensionais em tons de cinza, com resolução de 2,5 metros. O satélite possui ainda um avançado radar imageador, chamado PALSAR, para a captação de imagens através de microondas, podendo operar dia e noite, sob qualquer condição climática, com resolução de 10 metros. O PALSAR pode ser usado, entre outras aplicações, no mapeamento da Amazônia, onde a cobertura de nuvens dificulta a obtenção de imagens ópticas aproveitáveis. (Fonte: Disponível em: <http://www.ibge.gov.br/home/presidencia/noticias/nota_satelite.shtm>. Acesso em: 27 jan. 2007).

${ }^{19}$ Dornelles (1991) identifica uma série de mitos relativos às “imagens de satélite" que, senso comum, são consideradas como verdades últimas capazes de revelar muitas coisas acerca de nosso planeta. A respeito dos mitos em torno das "imagens de satélite” é interessante se ler: DORNELES, Beatriz Corrêa Pires. O Mito da Imagem de Satélite e sua Manipulação. 1991. 1233 f. Dissertação (Mestrado em Comunicação) Faculdade de Comunicação e Artes, USP, São Paulo, 1991. 
imitāmēntum e imitātor, que designam aquilo que pode ser imitado, a imitação/cópia e o imitador (o que imita), respectivamente. Tal terminologia ganha, segundo essa visão, conotação de imitação. Entrementes, significados diversos deste último podem ser considerados. Imagem pode estar relacionada, sobretudo na atualidade, a imagine (do inglês imaginar), o que remete a outros termos de origem latina, quais sejam, imāginārŭus, imāginātiōo e imāgĭnor, designando, de sua parte, o imaginário/imaginação, a imagem/visão, e a representação, respectivamente. Castrogiovanni (2004) defende que: "toda Imagem é/pode ser vista como uma similaridade [...] aparência” (p. 74). Segundo ele, a imagem traz significados variados e subjacentes a si mesma. Deste modo, pode trazer significâncias múltiplas para um único sujeito e significâncias ainda mais múltiplas para muitos sujeitos. É, portanto, a imagem, polissemia pura (cf. SANTANELA, 2006).

Os significados atribuídos a uma imagem dificilmente coincidirão entre os observadores, e, hodierno, bombardeiam toda e qualquer pessoa. Para Maffesoli (1995), na sociedade capitalista de consumo, a imagem adquire alto status: “A imagem, o simbólico, o imaginário, a imaginação voltam à cena [...] levados a representar um papel de primeiro plano. É o [...] mundo ‘imaginal'”. (p. 89).

No mundo imaginal atual "tudo" é passível de ser transformado em imagem. Telas e monitores estão em toda parte: LCD, CRT, PDP, FED, OLED, EL, FSA e outros mais. Outdoors, banners e cartazes convivem lado a lado, visto que "dispomos de várias possibilidades para transformar os pensamentos em formas variáveis.” (FRUTIGER, 1999, p. 6).

Num contexto histórico desse tipo, a imagem ganha credibilidade. É famoso o dito popular: "Uma imagem vale por mil palavras". O ditado, provavelmente originário do meio jornalístico, esconde a noção de que a imagem é a verdade e basta por si só.

O apelo à imagem é tão grande que, em seu marketing, algumas empresas fazem uso de propagandas que, de certa forma, criticam a própria noção que se tem de imagem. Ver a ilustração abaixo (Figura 3):

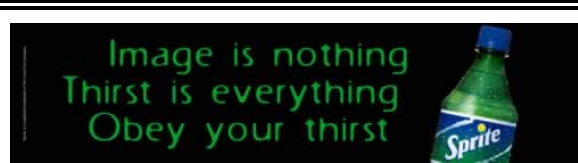

Figura 3 - Campanha publicitária do refrigerante Sprite ${ }^{\circledR}$, da multinacional Coca-Cola ${ }^{\circledR}$. Nela, pode-se ler que:

“Imagem não é nada. Sede é tudo. Obedeça sua sede”.

Fonte: Disponível em: <http://www.business2000.ie/cases/cases_6th/case10.htm>. Acesso em: 30 dez. 2006.

Flusser (1985) identifica na sociedade imaginal, o caráter mágico:

Podemos observar, hoje, de que forma se processa a magicização da vida: as im agens técnicas, atualmente onipresentes, ilustram a inversão da função imaginística e remagicizam a vida.

Trata-se da alienação do homem em relação a seus próprios instrumentos. O homem se esquece do motivo pelo qual imagens são produzidas: servirem de instrumentos para orientá-lo no mundo. Imaginação torna-se alucinação e o homem passa a ser incapaz de decifrar imagens, de reconstruir as dimensões abstraídas. (p. 8).

Fluser (1985) entende por imagens técnicas aquelas que produzidas e reproduzidas por aparelhos e que, por falta de uma análise crítica, acabam por se transformar em algo inquestionável. 
Neste ponto os professores enfrentam dilemas: os educandos da sociedade das imagens técnicas não querem/gostam de escrever. Os mestres procuram deixar o conteúdo aprazível por meio de imagens, e, nisso, caem numa armadilha: apresentam por verdade aquilo que a imagem só representa.

Nesse sentido, o presente texto passa, em seguida, a sugerir uma possível forma de ação para que o professor se utilize de imagens, mas faça isso de forma crítica. Apresentar-se-á o caso contextualizado numa aula de geografia, mas que pode ser considerado em outras áreas do conhecimento.

\section{ASPECTOS METODOLÓGICOS}

A presente pesquisa foi feita com estudantes de Ensino Médio de uma escola particular $^{20}$ de ensino, na cidade de Porto Alegre. Optou-se por realizar a presente pesquisa mediante a aplicação de uma oficina didático-pedagógica ${ }^{21}$, onde os educandos puderam, através de um processo interativo e coletivo, realizar as atividades propostas; ocasião na qual, concomitantemente, a presente investigação foi levada a cabo.

\subsection{INSTRUMENTOS DA PESQUISA}

Os instrumentos de pesquisa utilizados foram distribuídos como "atividade de sala de aula”, como segue:

Instrumento 1: Faça um desenho, um mapa do trajeto que percorres para chegar até a escola:

(Esclarecimento: O mapa deverá ser feito com base num mapa mental, ou seja, com base na memória, na lembrança do caminho percorrido para chegares até a escola. Use lápis, caneta hidrocor, símbolos (legendas), etc. Use a criatividade e a imaginação). - Obs.: note-se que o instrumento convida o educando a "soltar" a imaginação, o que pode permitir a emergência de percepções subjetivas, singulares e particulares; justamente o que se quer.

Instrumento 2: Localize na imagem de satélite (software Google Earth ${ }^{\mathrm{TM}}$ ) a sua casa e a escola (Obs.: na presente pesquisa os estudantes trabalharam diretamente em meio digital, em tela (no Laboratório de Informática da escola), e, também, em meio analógico (com folhas de papel que tinham escola e áreas de entorno impressas)): N.B.: trata-se de uma atividade de localização propriamente dita, onde a casa do aluno e a escola são observadas, localizadas e percebidas pelo estudante de modo diverso, agora, através das imagens orbitais.

\footnotetext{
${ }^{20}$ Por razões éticas os presentes autores preferem omitir o nome de instituição, bem como, identidades dos sujeitos da pesquisa.

${ }^{21}$ Como o objetivo do presente artigo é versar sobre a percepção (imagem) que os estudantes tinham (mapa mental) antes da visualização de uma imagem orbital e qual é a nova percepção depois disso, os presentes autores se eximirão de falar sobre oficinas didático-pedagógicas. Sugere-se, no entanto, para se ir além, a leitura dos seguintes artigos: SANTOS JÚNIOR, Donarte Nunes dos; LAHM, Regis Alexandre. Proposta de oficina pedagógica: os recursos do software Google Earth ${ }^{\mathrm{TM}}$, da (re)escrita e do desenho na educação espacial. Ciência \& Ensino (UNICAMP), v. 2, p. 1-14, 2007 e ROSA, Renata Urruth; SANTOS JÚNIOR, Donarte Nunes dos; LAHM, Regis Alexandre. O Recurso das Imagens de Satélite para Estudo do Lugar do Educando: uma experiência na área da Matemática e da Geografia. Experiências em Ensino de Ciências (UFRGS), v. V2, p. 23-36, 2007. Para saber ainda mais sobre aplicação de oficinas pedagógicas, especificamente na geografia, ler: GOULART, Lígia Beatriz. Dificuldades para Aprender Geografia: uma proposta de oficina de zona de desenvolvimento proximal. 1993. 174 f. Dissertação (Mestrado em Educação), Faculdade de Educação, PUCRS, Porto Alegre, 1993, às páginas 38 a 50 .
} 
Instrumento 3: Tendo por base a análise e a comparação entre o mapa mental (mapa) desenhado por você e a imagem orbital (na qual foi feita a localização de sua casa e da escola), expresse através de um texto a sua nova percepção acerca do lugar onde vives:

\subsection{MÉTODO DE ANÁLISE}

Cumpre informar que a presente pesquisa encontra sua abordagem naquilo que se pode chamar de fenomenológico-compreensiva ${ }^{22}$. Entende-se a abordagem fenomenológico-compreensiva, em concordância com o pensamento de Moraes (1993, 2005, 2007), como aquela que concebe que a "verdade" se manifesta na essência dos fenômenos. Em outras palavras, admite-se a existência de um mundo material, uma realidade objetiva, entretanto, acredita-se, que não se pode ter acesso completo a ela. Segundo essa concepção, que os presentes autores assumem, somente se pode ter acesso aos fenômenos, àquilo que se manifesta aos sujeitos. Tal concepção encontra rico respaldo na chamada geografia cultural, que se preocupa sobremaneira em investigar como os sujeitos percebem o espaço.

Assim, a realidade é entendida como sendo construída. Passa a ser conjunto de representações que os sujeitos da pesquisa (alunos e professor) fazem a partir das interações com o espaço.

A análise dos resultados da presente pesquisa foi feita com base nas sugestões de Moraes (2005). O teórico aponta para as possibilidades das análises textuais que se dão através de etapas, tais como "unitarização" do corpus da pesquisa e categorização das unidades construídas. Sendo assim, no dizer de Moraes (2005), os resultados desta pesquisa sofreram “[...] um processo de desconstrução seguida de reconstrução [...]” (p 87).

\subsection{ANÁLISE DOS RESULTADOS}

Para a realização da presente pesquisa optou-se pelo método da análise textual, nos moldes sugeridos por Moraes (2005), especificamente, adotando-se a priori a categoria imagem como referencial maior. Por outros termos, procurou-se nos desenhos e nos textos dos estudantes, a emergência de percepções relativas a mencionada categoria. Assim, para a "categorização" das idéias emergentes dos textos (categorias iniciais e intermediárias (MORAES, 2005)), foi preestabelecida, como categoria final a imagem.

O corpus resultante do atual estudo apresenta-se em três grandes grupos, sejam eles, dezesseis desenhos (chamados de mapas mentais), nos quais, os alunos comunicam, por as imagens que concebem de seu trajeto casa-escola, dezessete imagens de satélite, nas quais o aluno identificam tanto casa quanto escola e dezesseis textos, onde o aluno comunicam as suas novas percepções acerca do lugar onde vivem.

\subsection{INTERPRETAÇÃO DOS RESULTADOS}

O corpus da presente pesquisa será analisado, como já foi dito, sob as "lentes" da categoria imagem. Como nestas poucas páginas não é possível expor todos os

\footnotetext{
${ }^{22}$ Os presentes autores entendem fenomenologia, em Educação, em concordância com Moraes (1993), quando o teórico escreve que: "A Fenomenologia é ao mesmo tempo uma filosofia e um método de chegar à compreensão dos fenômenos, aquilo que se manifesta em si mesmo à consciência, que se dá, que se torna visível.” (p. 16).
} 
dezesseis desenhos (mapas mentais), as dezesseis imagens orbitais e os dezesseis textos que os educandos produziram, apresentar-se-á apenas um, que os autores julgam o mais representativo ${ }^{23}$.

Muitos foram os aspectos que emergiram a partir de uma visão imagética que os Sujeitos têm do espaço onde vivem. É interessante iniciar com a ilustração abaixo (Figura 4):

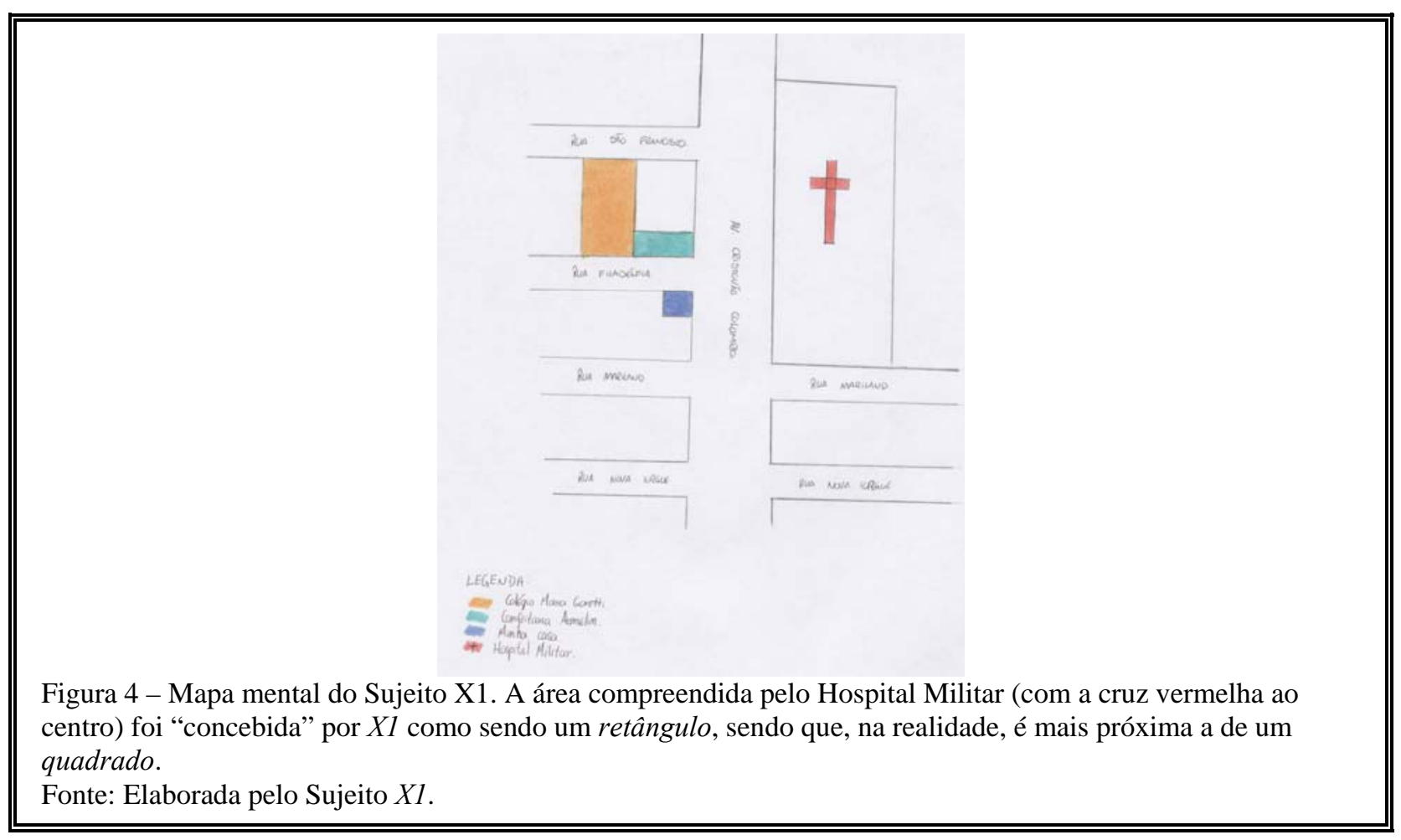

Na ilustração acima (Figura 4) uma área com características geométricas eminentemente tendendo para a figura geométrica de um quadrado, foi concebida como sendo um retângulo. Isso pode ser verificado através da respectiva imagem orbital da área em questão, ilustração abaixo (Figura 5):

\footnotetext{
${ }^{23}$ Para a consulta e o estudo pormenorizado das (re)construções espaciais feitas a partir da confrontação entre desenhos (mapas mentais, portanto), imagens orbitais (produtos advindos da tecnologia do Sensoriamento Remoto) e a manifestação destas (re)construções através de textos, consultar: SANTOS JÚNIOR, Donarte Nunes dos. Geografia do espaço percebido: uma educação subjetiva. 2007. 280 f. Dissertação (Mestrado em Educação em Ciências e Matemática). Faculdade de Física, PUCRS, Porto Alegre, 2007. Disponível em: <http://tede.pucrs.br/tde_busca/arquivo.php?codArquivo=974>. Acesso em: 08 mar. 2010
} 


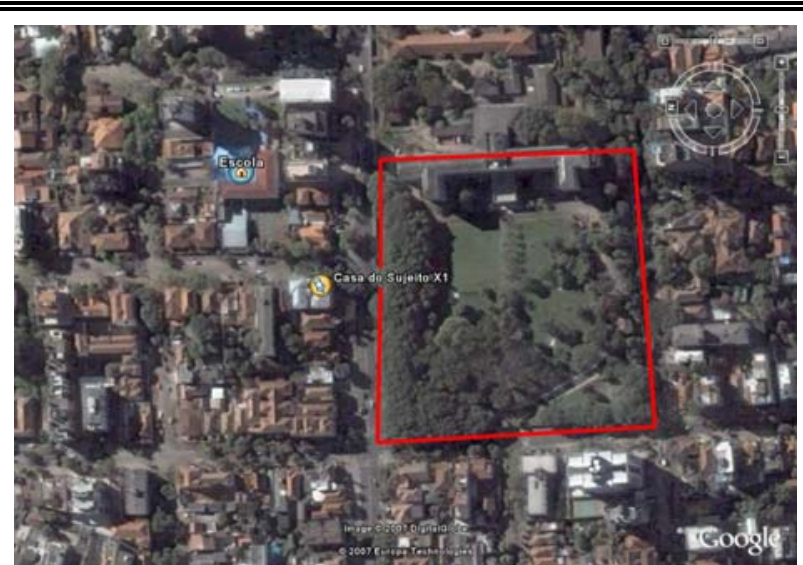

Figura 5 - Imagem de satélite da área desenhada pelo Sujeito X1. O traçado (linha vermelha) mostra que a forma da área compreendida pelo hospital assemelha-se a de um quadrado.

Fonte: Google Earth ${ }^{\mathrm{TM}}$ Mapping Service. Modificada pelo autor.

Na ilustração acima (Figura 5) é possível observar que a área identificada pelo Sujeito $X 1$ como sendo o quarteirão de um hospital tende para um quadrado e não para um retângulo como era, originariamente, a concepção espacial do Sujeito.

Após ter confrontado seu desenho com a imagem orbital, o mesmo sujeito expressou a sua nova percepção acerca do espaço através do seguinte texto:

[...] o que é diferente entre meu mapa mental é a proporção da área ocupada pelo Hospital Militar. A área ocupada pelo Hospital Militar começa na Rua Mariland e pela Rua Mariland acaba só na Rua Marques do Pombal. Ocupa toda essa área e pela Av. Cristóvão Colombo começa na esquina da Rua Mariland e acaba em um determinado ponto, passando um pouco da Rua São Francisco que é do outro lado da rua.

No meu mata mental representei o Hospital Militar com o formato de um retângulo, mas analisando melhor o mapa por satélite se percebe que o formato geométrico para melhor ser representado é um quadrado. (Sujeito $\mathrm{X} 1)$

Nota-se, a partir do texto do Sujeito, que ele agora, após ter confrontado seu desenho com a imagem orbital, delimita a área citada com as respectivas ruas, e, além disso, se dá por conta que a geometria idealizada é diferente da real, (re)construindo, portanto, tal a antiga noção.

\section{CONCLUSÃO}

A tecnologia do Sensoriamento Remoto, nomeadamente a das imagens orbitais, como se supunha, constituiu-se num precioso recurso que, confrontado com os desenhos, com os mapas mentais que os educandos tinham idealizado previamente, possibilitaram a (re)construção de tais noções espaciais. De sua parte, a oportunidade de expressar essa (re)construção espacial através de um texto, mostrou-se pertinente uma vez que, segundo o entender dos autores, serviu como atividade de fixação da nova noção.

\section{REFERÊNCIAS}

BARTHES, Roland. O óbvio e o obtuso. Rio de Janeiro: Nova Fronteira, 1990. 
BOLIGIAN, Levon, BOLIGIAN, Andressa Turcatel Alves. Geografia: espaço e vivência. São Paulo: Atual, 2004.

BORGES, Maria Elisa Linhares. História \& Fotografia. 2. ed. Belo Horizonte: Autêntica, 2005.

BRASIL. Ministério da Educação e do Desporto. Conselho Nacional de Educação. Câmara da Educação Básica. Resolução n. 2, de 7 abril de 1998. Institui as Diretrizes Curriculares Nacionais para o Ensino Fundamental. Diário Oficial da União. Brasília, DF, 15 abr. 1998ª .

. Ministério da Educação e do Desporto. Conselho Nacional de Educação. Câmara de Educação Básica. Parecer CEB n. 4/98. Diretrizes Curriculares Nacionais para o Ensino Fundamental. Brasília, DF: MEC/CNE, 1998b.

Lei de Diretrizes e Bases da Educação Nacional. Lei n 9.394/96,de 20 de dezembro de 1996. Estabelece as diretrizes e bases da educação nacional. Diário Oficial da União, Brasília, DF, 23 dez. 1996.

Ministério da Educação e do Desporto. Secretaria de Educação Fundamental.

Parâmetros Curriculares Nacionais Terceiro e Quarto Ciclos do Ensino Fundamental: introdução aos parâmetros curriculares nacionais. Brasília, DF: MEC/SEF, 1998.

Parâmetros Curriculares Nacionais para o Ensino Médio: Parte I — Bases Legais. Brasília, 1999.

CASTROGIOVAnNi, Antônio Carlos. A geografia do espaço turístico, como construção complexa da comunicação. 2004. 334 f. Tese (Doutorado) - Faculdade de Comunicação, PUCRS, Porto Alegre, 2004.

CRÓSTA, Álvaro Penteado. Processamento Digital de imagens de sensoriamento remoto. Campinas: IG/UNICAMP, 1993.

DORNELES, Beatriz Corrêa Pires. O Mito da Imagem de Satélite e sua

Manipulação. 1991. 1233 f. Dissertação (Mestrado em Comunicação) Faculdade de Comunicação e Artes, USP, São Paulo, 1991.

FLORENZANO, Teresa Gallotti. Imagens de satélite para estudos ambientais. São Paulo: Oficina de Textos, 2002.

FLUSSER, Vilém. Filosofia da Caixa Preta: Ensaios para uma futura filosofia da fotografia. São Paulo: Hucitec, 1985.

FRUTIGER, Adrian. Sinais e Símbolos: desenho, projeto e significado. São Paulo: Martins

Fontes, 1999.

GOULART, Lígia Beatriz. Dificuldades para Aprender Geografia: uma proposta de oficina de zona de desenvolvimento proximal. 1993. 174 f. Dissertação (Mestrado em Educação), Faculdade de Educação, PUCRS, Porto Alegre, 1993

HECHT, Eugene. Óptica. Lisboa: Fundação Calouste Gulbenkian, 2002.

LAHM, Regis Alexandre. Técnicas de Sensoriamento remoto e geoprocessamento aplicados a cartografia. In: CASTROGIOVANNI, A.C. Inquietações Geográficas. Porto Alegre: Dos Autores, 2000.

LANDIM, Paula da Cruz. Desenho de paisagem urbana: as cidades do interior 
paulista. São Paulo: Editora UNESP, 2004.

LYNCH, Kevin. A imagem da cidade. São Paulo: Martins Fontes, 1997.

MAFFESOLI, Michel. A contemplação do mundo. Porto Alegre: Artes e Ofícios, 1995.

MORAES, Roque de. Fenomenologia: uma introdução. Educação, Porto Alegre, v. 16, n. 24, p. 15-24, 1993.

Mergulhos Discursivos: análise textual qualitativa entendida como processo integrado de aprender, comunicar e interferir em discursos. In: GALIAZZI, Maria do Carmo e FREITAS, José Vicente de. Metodologias emergentes de pesquisa em educação ambiental. Ijuí: Unijuí, 2005.

MORAES, Roque de. Análise textual: discursiva. Ijuí: UNIJUÍ, 2007. 223 p.

POPP, José Henrique. Geologia Geral. 5. ed. Rio de Janeiro: LTC, 1998.

REIS, Norma Teresinha Oliveira et al. Análise da dinâmica de rotação de um satélite artificial: uma oficina pedagógica em educação espacial. Rev. Bras. Ensino Fís., São Paulo, v. 30, n. 1, $2008 . \quad$ Disponível em: $<$ http://www.scielo.br/scielo.php?script=sci_arttext\&pid=S1806$11172008000100011 \& \operatorname{lng}=\mathrm{en} \& n r m=\mathrm{iso}>$. Acesso em 24 mar. 2010.

ROSA, Renata Urruth; SANTOS JÚNIOR, Donarte Nunes dos; LAHM, Regis Alexandre. O Recurso das Imagens de Satélite para Estudo do Lugar do Educando: uma experiência na área da Matemática e da Geografia. Experiências em Ensino de Ciências (UFRGS), v. V2, p. 23-36, 2007.

SANTOS JÚNIOR, Donarte Nunes dos. Geografia do espaço percebido: uma educação subjetiva. 2007. 280 f. Dissertação (Mestrado em Educação em Ciências e Matemática). Faculdade de Física, PUCRS, Porto Alegre, 2007. Disponível em: $<$ http://tede.pucrs.br/tde_busca/arquivo.php?codArquivo=974>. Acesso em: $08 \mathrm{mar}$. 2010.

; LAHM, Regis Alexandre. Proposta de oficina pedagógica: os recursos do software Google Earth $^{\mathrm{TM}}$, da (re)escrita e do desenho na educação espacial. Ciência \& Ensino (UNICAMP), v. 2, p. 1-14, 2007

SANTOS, Vânia Maria Nunes dos. O uso escolar das imagens de satélite: socialização da ciência e tecnologia espacial. In: PENTEADO, Heloisa Dupas (Org.). Pedagogia da comunicação. São Paulo: Cortez, 1998.

Escola, cidadania e novas tecnologias: Investigação sobre experiências de ensino com o uso de sensoriamento remoto. São Paulo. 150p. Dissertação de Mestrado. Faculdade de Educação da USP. 1999.

Escola, cidadania e novas tecnologias: o sensoriamento remoto no ensino. São Paulo: Paulinas, 2002.

SANTANELA, Lucia. Por uma Epistemologia das Imagens Tecnológicas: seus modos de apresentar, indicar e representar a realidade. In: ARAUJO, Denize Correa. Imagem (ir)realidade: comunicação e cibernética. Porto Alegre: Sulina, 2006.

TUAN, Yi-Fu. Topofilia. São Paulo: Difel, 1980.

VESENTINI, José William. Sociedade e Espaço: geografia geral e do Brasil. São Paulo: Ática, 2005. 